\title{
Interactive comment on "ISBA-MEB (SURFEX v8.1): model snow evaluation for local-scale forest sites” by Adrien Napoly et al.
}

\section{Anonymous Referee \#2}

Received and published: 9 September 2020

This study presents the evaluation of the ISBA-MEB snow model in 3 forest sites in Canada. Despite being based only on 3 stations, these are well known and with good quality observations that allow a detailed evaluation as presented in this study. A sensitivity analysis is also performed and identifies 1 important parameters of the MEB scheme which is relevant for the snow simulations. This is a relevant study for the snow community as it highlights several processes important in the modeling of snow and soil conditions in forest areas. It is also relevant for a wider climate community due to the role of these areas in the response to a warmer climate. The manuscript is well organized and clear. I only found a few details, listed below, that require some attention from the authors.

Fig. 1 legend is missing 
Fig.2 Which snow density was assumed ? Snow cover fraction is a function of snow depth $(D, m)$ and not Snow Water equivalent. Please indicate which density is used, or plot snow fraction as function of snow depth.

Line 288: "In order To" : "In order to"

Line 367: Defining last day of snow when $S N D<0.2 \mathrm{~m}$ and below that for the following two weeks. The mean annual cycle of snow depth in Figure 6 shows that ISBA simulations on average never reach $20 \mathrm{~cm}$ of snow depth in the OAS site. In years when SND is always $<0.2$ how does this identification of last day of snow works in a simulation? A value of 0.1 seems more reasonable. Would changing from $20 \mathrm{~cm}$ to $10 \mathrm{~cm}$ change significantly the metrics in Table 5 ?

Line 377; "Also, Fig. 5 seems to indicate that the snow density is well modeled since underestimation or overestimation of SND and SWE are consistent for both models." This is true for OAS and OJP, but the OBS results in year 2 and 3 (Fig 5) indicate a reasonable performance of snow depth but a large underestimation of snow mass in year 2 and over-estimation in year 3 (also OJP in year 3 ). Could this be related with snow density errors linked with different winter conditions between year 2 and 3 ?

Fig 7. Missing panel names $(a, b, c)$ which are used in the text (e.g. line 399). The 3rd datetick seems wrong "03/29/2006" should be "03/28/2006" ?

Line 437: Suggest to remove "somewhat"

Interactive comment on Geosci. Model Dev. Discuss., https://doi.org/10.5194/gmd-2020-165, 2020. 